\title{
Mycoplasma ovipneumoniae-derived lipid- associated membrane proteins induce cytokine secretion in mouse peritoneal macrophages through TLR2 signalling
}

\section{Fan Bai}

Inner Mongolia Agricultural University https://orcid.org/0000-0003-4247-2383

Jindi Wu

Inner Mongolia Agricultural University

Bo Liu

Inner Mongolia Agricultural University

Xiaohui Wang

Inner Mongolia Agricultural University

Xiaona Shi

Inner Mongolia Agricultural University

Tianxing Lv

Inner Mongolia Agricultural University

\section{Yanfang Wang}

Inner Mongolia Agricultural University

Yongqing Hao ( $\nabla$ haoyq1960@163.com )

https://orcid.org/0000-0002-1520-1193

Research article

Keywords: Mycoplasma ovipneumoniae, TLR2, lipid-associated membrane protein, inflammasome, cytokines

Posted Date: December 13th, 2019

DOI: https://doi.org/10.21203/rs.2.18824/v1

License: (9) (1) This work is licensed under a Creative Commons Attribution 4.0 International License. Read Full License 
Version of Record: A version of this preprint was published at Research in Veterinary Science on October 1st, 2020. See the published version at https://doi.org/10.1016/j.rvsc.2020.07.022. 


\section{Abstract}

Background: Mycoplasma ovipneumoniae (M. ovi) is the causal pathogen of chronic non-progressive pneumonia infections in sheep, goats, bighorn, and wild small ruminants. However, the mechanism of infection and immune response to $M$. ovi remain unclear. Invading microbes express lipid-associated membrane proteins (LAMPs) on the cell surface that interact with host cells to facilitate infection, and are thus the major molecules recognised by the host immune system. Upon LAMP recognition, Toll-like receptor 2 (TLR2) and NLRP3 inflammasome sense the pathogens and signalling pathways for cytokine secretion. In this study, we investigated whether $M$. ovi and $M$. ovi-derived LAMPs are immunobiologically active compounds capable of activating mouse peritoneal macrophages and explored the underlying mechanism.

Results: After infection of wild-type mice with M. ovi, the expression of TLR2 and NLRP3 at the transcription and translational levels was determined with reverse transcription-polymerase chain reaction and flow cytometry. In addition, the cytokine levels and associated pathways were detected in infected wild-type, $\mathrm{T} / \mathrm{r} 2^{-1}$, and $\mathrm{N} / \mathrm{rp} 3^{-/}$mice via enzyme-linked immunosorbent assaying and western blotting. The nuclear factor (NF)-кB and mitogen-activated protein kinase (MAPK) signalling pathways were found to mediate the expression of inflammatory cytokines in M. ovi or M. ovi-derived LAMPsinfected peritoneal macrophages, and cytokines were not induced in $\mathrm{Tlr}^{2 /-}$ and/or $\mathrm{N} / \mathrm{rp} 3^{--}$macrophages.

Conclusion: Host cytokine production is activated in response to M. ovi-derived LAMPs through the NF-KB and MAPK signalling pathway via TLR2.

\section{Background}

Mycoplasmas are a well-studied heterogeneous group of small parasitic microorganisms that capable of self-replication, and are characterised by a wall-less envelope. These parasites cause numerous types of infections in humans and other mammals. Among these, Mycoplasma ovipneumoniae (M. ovi) causes a chronic non-progressive pneumonia infection in sheep, goats, bighorn, and wild small ruminants [1-4], which has resulted in a worldwide epidemic and enormous financial losses to the sheep industry $[2,4,5]$. Despite extensive efforts to understand the mechanisms underpinning M. ovi infection, the molecular basis of macrophage responses to $M$. ovi infection remains largely unknown.

Lipid-associated membrane proteins (LAMPS) are a mixture of bacterial lipoproteins expressed on the cell surface that act as the primary interacting structures with host cells [6]. LAMPs from several mycoplasmas have been demonstrated to be biologically active, and are considered to be the most potent initiators of inflammatory reactions in response to Mycoplasma infection [7-10]. Through direct interaction with the host cells, LAMPs can influence the functions of macrophages, monocytes, and brain astrocytes to trigger proinflammatory cytokine production or, in some cases, necrosis or apoptosis to evade the host immune response and facilitate infection [11]. Thus, gaining a better understanding of the 
Mycoplasma LAMP-triggered molecular mechanisms of host cells will provide important insight into the molecular pathogenesis of Mycoplasma infection $[6,10,12,13]$.

Recent evidence points to an important role for Toll-like receptors (TLRs) in the early innate recognition and inflammatory responses of the host against invading microbes $[14,15]$. TLRs are a highly conserved family of type I transmembrane receptors that recognise specific pathogen-associated molecular patterns, including LAMPs, lipopolysaccharide, lipotechoic acid, and other bacterial wall components, and their recognition of purified Mycoplasma LAMPs is well documented. Specifically, TLR1, TLR2, and TLR6 are implicated in the recognition of LAMPs stemming from several Mycoplasma strains $[10,12,13,16$, 17]. TLR2 dimerises with either TLR1 or TLR6 to enhance the recognition of lipoproteins, thereby augmenting the cellular cytokine response [18].

In addition to the important role of TLR signalling in the response of peritoneal macrophages to various extracellular stimuli, including Mycoplasma infection [12, 16], Mycoplasma hyorhinis was shown to be capable of activating the NLRP3 inflammasome, resulting in the induction of interleukin (IL)-1 $\beta$ [19]. Therefore, we hypothesised that $M$. ovi and $M$. ovi-derived LAMPs are also immunobiologically active compounds that trigger the host immune system via TLRs and the NRLP3 inflammasome.

To determine the involvement of TLR2 and the NLRP3 inflammasome in M. ovi or M. ovi-derived LAMPsinduced peritoneal macrophage cytokine protein expression, we performed experiments using peritoneal macrophages from infected C57BL/6J (wild-type, WT) and TLR2-deficient $\left(T / r 2^{\prime-}\right)$ or NRLP3- deficient $\left(\mathrm{Nr} / \mathrm{P3}^{--}\right)$mice with $\mathrm{M}$. ovi or M. ovi-derived LAMPs, and evaluated the cytokine production and activated pathways. These findings can provide important insight into the mechanism of infection and suggest targets for the treatment and prevention of $M$. ovi pneumonia infections in economically important livestock.

\section{Results}

\section{ovi and M. oviderived LAMPs increase TLR2 and NLRP3 surface expression in macrophages}

The transcription levels of T/r2 and N/rp3 inflammasome were significantly increased after induction by M. ovi or M. ovi-derived LAMPs at different doses and time points. The mRNA expression of T/r2 and NIrp3 inflammasome peaked at $8 \mathrm{~h}$ post-stimulation by M. ovi [multiplicity of infection (MOI) 4:1], after which it decreased gradually ( 4 vs. 8 h, $\mathrm{P}<0.001$ ) (Figure 1a, c). Eight hours after mouse peritoneal macrophages were incubated with $10^{7}$ and $10^{8} \mathrm{M}$. ovi, the mRNA levels of T/r2 and N/rp3 inflammasome showed significant differences. Furthermore, $8 \mu \mathrm{g}$ of $M$. ovi-derived LAMPs induced high T/r2 and NIrp3 mRNA expression levels at the indicated times post-infection (Figure 1e, g). Various concentrations of LAMPs significantly increased the mRNA levels of Tlr2 and N/rp3 at $8 \mathrm{~h}(\mathrm{P}<0.001)$ (Figure 1f, $\mathrm{h}$ ). Consistent the reverse transcription-quantitative polymerase chain reaction (RT-qPCR) results, those from flow cytometry and western blotting demonstrated that TLR2 and NLRP3 inflammasome protein expression was increased at $16 \mathrm{~h}(\mathrm{P}<0.001)$ after $M$. ovi or $M$. ovi-derived LAMPs treatment (Figure $1 \mathrm{i}, \mathrm{j})$. 


\section{Nuclear factor (NF)-KB, mitogen-activated protein kinase (MAPK), and caspase-1 signalling pathways are involved in the response to $M$. ovi and $M$. ovi-derived LAMPs in mouse peritoneal macrophages}

To determine whether blocking the functions of TLR2 or the NLRP3 inflammasome affected the activation of JNK, ERK, p38, p65, and caspase-1, which drive IL-1 $\beta$ protein expression, peritoneal macrophages of C57BL/6J WT, $\mathrm{Tlr} 2^{-1}$, and $\mathrm{NIrp3}^{-/-}$mice were exposed to the same concentration of $M$. ovi or M. ovi-derived LAMPs.

In line with the upregulation of TLR2 and NLRP3 expression, activation of NF-KB, MAPK, and caspase-1 signalling pathways was observed in cell proteins of C57BL/6J WT mouse peritoneal macrophages stimulated with M. ovi or M. ovi-derived LAMPs as compared with the unstimulated control (Figure 2a-d).

Specifically, in the MAPKs and NF-KB pathway, the phosphorylation of JNK, ERK, p38, and p65 was remarkably upregulated after infection; however, this upregulation was suppressed in $T / r^{-/-}$peritoneal macrophages (Figure 2a, b).

In the caspase-1 pathway, caspase-1 was upregulated in C57BL/6J WT mice peritoneal macrophages after M. ovi or M. ovi-derived LAMPs infection at 3, 6, and $9 \mathrm{~h}$, which was inhibited in $\mathrm{NIrp3}^{/-}$and $\mathrm{Tlr} \mathrm{F}^{/-}$ peritoneal macrophages (Figure 2c-f).

In line with the observed upregulation of caspase-1, M. ovi and M. ovi-derived LAMPs induced the expression of pro-IL-1 $\beta$ and mature IL-1 $\beta$ in WT mice (Figure $2 c-h)$. However, this increase both in pro-IL$1 \beta$ and mature IL-1 $\beta$ was not detected in $T /{ }^{2} 2^{--}$mice. Of note, neither pro-IL-1 $\beta$ nor mature IL-1 $\beta$ were significantly affected when stimulated by $M$. ovi. However, when $M$. ovi-derived LAMPs served as the stimulus, the induction of mature IL-1 $\beta$ was found to be suppressed in $N / r p 3^{/-}$mice.

\section{ovi or M. ovi-derived LAMPs-induced IL-1 $\beta$ depends on TLR2}

Compared to the control, the IL-1 $\beta$ secretion levels were remarkably upregulated after $M$. ovi or $M$. oviderived LAMPs infection for $9 \mathrm{~h}$ in cultures of WT and $\mathrm{NIrp3}^{-/-}$peritoneal macrophages. However, compared to the WT peritoneal macrophages, the IL-1 $\beta$ levels were lower in the cultures of $\mathrm{NIrp3}^{1-}$ peritoneal macrophages. Moreover, compared to the control, IL-1 $\beta$ did not change significantly after treatments in cultures of $T / r 2^{-1-}$ cells (Figure 3 ).

\section{Discussion}

ovi is an etiological pathogen that is a major contributing factor to the occurrence of primary atypical pneumonia [22, 23], and the recent epidemic of $M$. ovi has caused great economic losses to the global sheep industry [24]. Herein, we demonstrated that NF-KB and MAPK pathway activation are involved in 
the response of peritoneal macrophages to $M$. ovi and M. ovi-derived LAMPs infection via the macrophage TLR2.

TLR2 recognizes a wide range of pathogen-associated molecular patterns derived from various pathogens, including mycoplasma, bacteria, fungi, parasites, and viruses, and is regarded as the major molecule by which the host recognizes invading microorganisms [25]. Upon microbial contamination, TLR2 senses the pathogens and triggers the synthesis of pro-IL-1 $\beta$. At the same time, NLRP3 activates caspase-1, which is an active protease that cleaves the precursor form of cytokines, including pro-IL-1 $\beta$, into mature, secreted forms [26]. Several other studies found that the LAMPs of other Mycoplasma species activate NF-KB via TLR-1, 2, 6, and induce expression of proinflammatory cytokines in monocytes and macrophages $[13,27]$.

Cytokines play an important biological role in pathogen clearance and induction of effective adaptive immunity [28]; thus, studies on how Mycoplasma induces host cytokine secretion can provide the key to understanding the complex mechanism of infection [10]. We demonstrated that $M$. ovi and M. ovi-derived LAMPs significantly induced TLR2 and NLRP3 inflammasome expression in peritoneal macrophages of C57BL/6J WT mice at both the transcription and translation levels. In addition, NF-KB and MAPK pathways were activated in C57BL/6J WT or $\mathrm{NIrp3}^{-1-}$ mice after infection, but such activation did not occur in $\mathrm{T} / \mathrm{r} 2^{\prime-}$ mouse peritoneal macrophages, and both $\mathrm{NIrp3}^{/-}$and $\mathrm{TIr}^{\prime-}$ peritoneal macrophages exhibited impaired caspase-1 activation. Consequently, lack of TLR2 prevented cytokine secretion in response to infection. Collectively, these findings suggest that the release of proinflammatory cytokines, along with NF-KB and MAPK signalling pathway activation, are dependent on the presence of macrophage secreted TLR2.

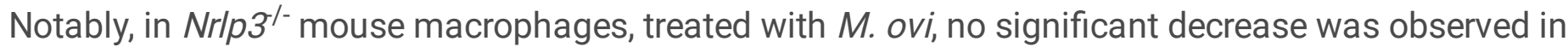
mature IL-1 $\beta$ ( $p 17$ ) protein. However, when the stimulus was LAMPs, IL-1 $\beta$ was found to be markedly reduced. Zhongjia Jiang et al have reported that capsular polysaccharide (CP) is a primary component of $M$. ovi in the pathogen-induced Toll-like receptor-mediated inflammatory responses in sheep airway epithelial cells [29]. However, several other inflammasome sensors e.g. AIM2, PYRIN, and NLRC4 may also be involved in induction of mature IL-1 $\beta$ expression. We suspect that when $\mathrm{M}$. ovi stimulates $\mathrm{Nr}_{\mathrm{f}} \mathrm{P}^{-1-}$ mice, antigenic substances such as CP in $M$. ovi, much than LAMPs, can induce the maturation of IL-1 $\beta$ by other means, which might have compensated for this deficiency.

\section{Conclusion}

Based on the findings of previous studies and our results, we conclude that M. ovi and M. ovi-derived LAMPs are immunobiologically active compounds that activate mouse peritoneal macrophages through the NF-KB and MAPK signalling pathways via TLR2. These results serve to further the current understanding of the complex mechanisms associated with $M$. ovi infection. 


\section{Methods}

\section{Bacterial strain, culture, and LAMP extraction}

ovi wild strain NM2010 was isolated from sheep in Inner Mongolia Autonomous Region in China and preserved in our lab. The strain was maintained in modified pleuropneumonia-like organism (PPLO) medium for $M$. ovi supplemented with yeast extract $(100 \mathrm{~mL} / \mathrm{L})$, inactivated horse serum $(200 \mathrm{~mL} / \mathrm{L})$, penicillin $(200 \mathrm{IU} / \mathrm{mL})$, and $0.4 \%$ phenol red $(\mathrm{w} / \mathrm{v})$, and the $\mathrm{pH}$ was adjusted to 7.5 with $0.5 \mathrm{M} \mathrm{NaOH}$. The titre of $M$. ovi culture was determined by a colony-forming assay using agar plates, and is presented as colony-forming units (CFU)/mL [20].

The preparation of LAMPs was performed as described previously [10]. In brief, M. ovi was cultivated in PPLO medium until reaching the stationary growth phase, and the sample was then pelleted by centrifugation for $10 \mathrm{~min}$ at $12,000 \mathrm{xg}$. The pellets were washed with endotoxin-free phosphate-buffered saline (PBS; Hyclone, Logan, UT, USA) and resuspended in $5 \mathrm{~mL}$ of Tris-buffered saline (50 mM Tris-Cl, $\mathrm{pH}$ 8.0, $0.15 \mathrm{M} \mathrm{NaCl}$ ) containing $1 \mathrm{mM}$ ethylenediaminetetraacetic acid (TBSE), solubilised by adding Triton $\mathrm{X}-114$ to a final concentration of $2 \%$, and incubated at $4{ }^{\circ} \mathrm{C}$ for $1 \mathrm{~h}$. The lysate was incubated at $37^{\circ} \mathrm{C}$ for $10 \mathrm{~min}$ for phase separation. After centrifugation at 10,000 $\mathrm{xg}$ for $20 \mathrm{~min}$, the upper aqueous phase was discarded and replaced by the same volume of TBSE. The solution was then vortexed and incubated at 4 ${ }^{\circ} \mathrm{C}$ for $10 \mathrm{~min}$, and the phase separation procedure was repeated twice. The final Triton X-114 phase was resuspended in TBSE to the original volume, 2.5 volumes of ethanol were added to precipitate the membrane components, and the solution was incubated at $-20^{\circ} \mathrm{C}$ overnight. After centrifugation, the pellet was suspended in endotoxin-free PBS, and then sonicated for $30 \mathrm{~s}$. The protein concentration of the suspension was measured with the Coomassie Protein Assay Reagent (Pierce).

\section{Animals and macrophage isolation}

C57BL/6J WT and TIr $2^{-1-}$ mice were provided by the Model Animal Research Center of Nanjing University,

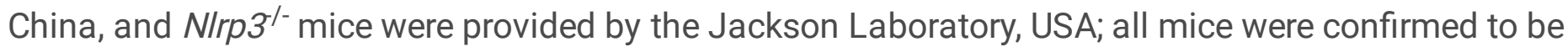
viral and Mycoplasma-free. The mice used in the experiments were 6-10 weeks of age.

For extraction of peritoneal macrophages, the mice were injected with $2 \mathrm{~mL}$ of $3 \%$ thioglycollate medium (BD Biosciences, Sparks, MD) and then killed with carbon dioxide. Peritoneal macrophages were isolated by washing the peritoneal cavity with endotoxin-free PBS and cultured at $37^{\circ} \mathrm{C}$ in $5 \% \mathrm{CO}_{2}$ in RPMI 1640 medium supplemented with $10 \%$ foetal bovine serum (Hyclone). The macrophages were identified by flow cytometry using a phycoerythrin (PE)-conjugated specific anti-CD11b antibody (M1/70, Biolegend, San Diego, CA, USA). Animal corpses were performed harmless treatment when the experiments finished.

Primary mouse peritoneal macrophages were plated at $2.5 \times 10^{6}$ cells/well onto six-well tissue culture treated plates, and incubated with or without various concentrations of $M$. ovi or M. ovi-derived LAMPs 
for various times relevant to the assays described below.

\section{RNA extraction and RT-qPCR analysis}

The total RNA of cells in different treatment groups was isolated at 4, 8, and $12 \mathrm{~h}$ post-stimulation by TRIzol reagent according to the manufacturer's instructions (Invitrogen, Carlsbad, CA, USA), and reversetranscribed to synthesise first-strand cDNA using M-MLV reverse transcriptase (TaKaRa, Dalian, China). qPCR was then performed in the 7500 real-time PCR System (Applied Biosystems, Foster City, CA, USA) using TaKaRa SYBR Green I kit (Takara, Dalian, China) with the following thermal cycling programme: 95 ${ }^{\circ} \mathrm{C}$ for $30 \mathrm{~s}, 40$ cycles of $95^{\circ} \mathrm{C}$ for $5 \mathrm{~s}$ and $60^{\circ} \mathrm{C}$ for $34 \mathrm{~s}$, followed by $95^{\circ} \mathrm{C}$ for $15 \mathrm{~s}, 60^{\circ} \mathrm{C}$ for $1 \mathrm{~min}$, and $95^{\circ} \mathrm{C}$ for $15 \mathrm{~s}$. The primer sets used for RT-qPCR were designed and synthesised by Shanghai Sangon Biotech Inc. (Shanghai, China) using bioinformatics tools based on available mRNA sequences, and the following primers were used to amplify specific genes: TIr2 (GenBanK ID: NM_011905) forward 5'TTTGCTCCTGCGAACTCC-3' and reverse 5'-GCCACGCCCACATCATTC-3'; NIrp3 (GeneBanK ID: NM_145827.4) forward 5'-ATTACCCGCCCGAGAAAGG-3' and reverse 5'-TCGCAGCAAAGATCCACACAG3'. Gene expression levels were normalized to the expression of Gapdh as described previously [21]. In each independent experiment, the mean gene expression ratios obtained with uninfected cultures were given a value of 1 (fold). The specificity of PCR was determined by sequencing of the PCR products.

\section{Enzyme-linked immunosorbent assay (ELISA)}

Secretion levels of the inflammatory cytokines (IL-1 $\beta)$ in cell-free supernatants of macrophages treated with M. ovi, M. ovi-derived LAMP, or control cells were analysed using the commercial mouse IL-1 $\beta$ ELISA Reagent Kit (Thermo) according to the manufacturer's instruction.

\section{Western blot analysis}

Sixteen to 18 hours before mouse peritoneal macrophages were incubated with or without the same concentration of M. ovi or M. ovi-derived LAMPs, they were seeded at $2.5 \times 10^{6}$ cells/well in six-well tissue culture treated plates. The cells were washed twice using PBS, harvested, and lysed for total cellular protein extraction at $15,30,60$ and 120 min or at 3, 6, and $9 \mathrm{~h}$ post-stimulation. The concentrations of the protein samples were determined using BCA assay kits (Pierce). For western blotting analysis, $10 \mu \mathrm{g}$ of total protein per lane was separated by $10 \%$ sodium dodecyl sulphate-polyacrylamide gel electrophoresis and blotted onto polyvinylidene fluoride membranes. Rabbit anti-phospho-JNK, anti-phospho-ERK, antiphospho-p38, and anti-phospho-NF-KB p65 monoclonal antibodies (Cell Signaling Technology, Beverly, MA, USA) were used for protein detection, and corresponding antibodies were used for detection of unphosphorylated molecules; rabbit anti-pro caspase-1 + p10 + p12 monoclonal antibody (1:2,000, 
Abcam, UK) and goat anti-pro-IL-1 $\beta$ polyclonal antibody (1:1,000, pIL-1 $\beta$, R\&D Systems, USA) were used for protein detection; rabbit anti-NLRP3 monoclonal antibody $(1: 1,000,15101 \mathrm{~S}, \mathrm{CST}$, USA) was used for protein detection. GAPDH was detected by a rabbit anti-GAPDH polyclonal antibody (GeneTex, San Antonio, TX, USA). Proteins were visualized using secondary horseradish peroxidase-conjugated goat anti-rabbit or donkey anti-goat antibodies (1:10,000, Abcam, UK). Signals were visualized using a SuperSignal West Pico Luminol Kit (Pierce; Termo Fisher Scientific). The images were captured using a MicroChemi 4.2 system (DNR Bio Imaging Systems, Jerusalem, Israel). Intensities of bands were measured with the public ImageJ program (National Institutes of Health, Bethesda, MD, USA; available at http://rsb.info.nih.gov/ij).

\section{Flow cytometry analysis}

Macrophages were incubated with or without various concentrations of M. ovi or M. ovi-derived LAMPs for $16 \mathrm{~h}$. The cells were stained with PE-conjugated anti-TLR2 (mT2.7, eBioscience, USA). Data were analysed using Flowjo 7.6 software (Treestar, Ashland, OR, USA).

\section{Statistical analysis}

The data of RT-qPCR and ELISA were analysed using GraphPad Prism 5 (GraphPad InStat Software, San Diego, CA, USA). Multigroup comparisons were performed with two-way analysis of variance. Data are expressed as the mean \pm standard deviation (SD). $P$ values less than 0.05 were considered statistically significant.

\section{Abbreviations}

ovi Mycoplasma ovipneumoniae

LAMPs lipid-associated membrane proteins

TLR2 Toll-like receptor 2

NF-kB nuclear factor-kB

MAPK mitogen-activated protein kinase

IL-1 $\beta$ interleukin-1 $\beta$

\section{Declarations}


Ethics approval and consent to participate

All animal experiments were conducted in accordance with the experimental practices and standards approved by the Animal Welfare and Research Ethics Committee of Inner Mongolia Academy of Agriculture and Animal Husbandry Sciences (Approval ID: 20170509-01) and all efforts were made to minimize animal suffering.

Consent for publication

Not applicable

Availability of data and materials

The data can be provided by the corresponding author on reasonable request.

Competing interests

The authors declare that they have no competing interests.

Funding

The Special Fund for Transformation of Scientific and Technological Achievements of Inner Mongolia Agricultural University (YZGC2017027) and the Science and Technology Project of Inner Mongolia Autonomous Region (201802066) provided funding to support this work. The funders had no role in study design, data collection, analysis and interpretation, decision to publish, or preparation of the manuscript.

Author contributions

FB and $\mathrm{YH}$ conceived of the study. FB and BL collected and curated the data. TL, YW, and XS analysed the data. $\mathrm{YH}$ obtained funding. FB, JW, and XW, and XS performed the experiments. FB, $\mathrm{YH}$, and JW supervised the project. All authers have read and approved the manuscript.

Acknowledgements

Not applicable

\section{References}


1. Besser TE, Frances Cassirer E, Highland MA, Wolff P, Justice-Allen A, Mansfield K, et al. Bighorn sheep pneumonia: Sorting out the cause of a polymicrobial disease. Prev Vet Med. 2013;108:85-93.

2. Nicholas RAJ. Improvements in the diagnosis and control of diseases of small ruminants caused by mycoplasmas. Small Rumin Res. 2002;45:145-149.

3. Parham K, Churchward CP, McAuliffe L, Nicholas RAJ, Ayling RD. A high level of strain variation within the Mycoplasma ovipneumoniae population of the UK has implications for disease diagnosis and management. Vet Microbiol. 2006;118:83-90.

4. Xin J, Li Y, Nicholas RAJ, Chen C, Liu Y, Zhang MJ, et al. A history of the prevalence and control of contagious bovine pleuropneumonia in China. Vet J. 2012;191:166-170.

5. Chen C, Qiao J, Meng QL, Hu ZX, Ma Y, Cai XP, et al. Serological and molecular survey of sheep infected with Mycoplasma ovipneumoniae in Xinjiang, China. Trop Anim Health Prod. 2015;47:1641-1647.

6. Rottem S. Interaction of mycoplasmas with host cells. Physiol Rev. 2003;83: 417-432.

7. Dhandayuthapani S, Rasmussen WG, Baseman JB. Stability of cytadherence-related proteins P140/P110 in Mycoplasma genitalium requires MG218 and unidentified factors. Arch. Med. Res. 2002;33:1-5.

8. Fleury B, Bergonier D, Berthelot X, Peterhans E, Frey J, Vilei EM. Characterization of P40, a cytadhesin of Mycoplasma agalactiae. Infect Immun. 2002;70:5612-5621.

9. Narita $\mathrm{M}$, Tanaka $\mathrm{H}$, Togashi T, Abe S. Cytokines involved in CNS manifestations caused by Mycoplasma pneumoniae. Pediatr Neurol. 2005;33:105-109.

10. Wang Y, Liu S, Li Y, Wang Q, Shao J, Chen Y, et al. Mycoplasma bovis-derived lipid-associated membrane proteins activate IL-1 $\beta$ production through the NF-KB pathway via toll-like receptor 2 and MyD88. Dev Comp Immunol. 2016;55:111-118.

11. Rawadi G. Mycoplasma fermentans interaction with monocytes/macrophages: molecular basis. Microb Infect. 2000;2:955-964.

12. Shimizu T, Kida Y, Kuwano K. A dipalmitoylated lipoprotein from Mycoplasma pneumoniae activates NF-kappa B through TLR1, TLR2, and TLR6. J Immunol. 2005;175:4641-4646.

13. He J, You X, Zeng Y, Yu M, Zuo L, Wu Y. Mycoplasma genitalium-derived lipid-associated membrane proteins activate NF-kappa B through Toll-like receptors 1, 2, and 6 and CD14 in a MyD88-dependent pathway. Clin Vaccine Immunol. 2009;16: 1750-1757.

14. Kopp EB, Medzhitov R. The Toll-receptor family and control of innate immunity. Curr Opin Immunol. 1999;11:13-18. 
15. Akira S, Takeda K. Toll-like receptor signalling. Nat Rev Immunol. 2004;4:499-511.

16. Shimizu T, Kida Y, Kuwano K. A triacylated lipoprotein from Mycoplasma genitalium activates NFkappa B through toll-like receptor 1 (TLR1) and TLR2. Infect Immun. 2008;76:3672-3678.

17. Yu Y, Chen Y, Wang Y, Li Y, Zhang L, Xin J. TLR2/MyD88/NF-KB signaling pathway regulates IL-1 $\beta$ production in DF-1 cells exposed to Mycoplasma gallisepticum LAMPs. Microb Pathog. 2018;117:225231.

18. Love W, Dobbs N, Tabor L, Simecka JW. (2010) Toll-like receptor 2 (TLR2) plays a major role in innate resistance in the lung against murine Mycoplasma. Plos One. 2010;5:e10739.

19. Xu Y, Li H, Chen W, Yao X, Xing Y, Wang X, et al. Mycoplasma hyorhinis activates the NLRP3 inflammasome and promotes migration and invasion of gastric cancer cells. Plos One. 2013;8:e77955.

20. Hardy RD, Jafri HS, Olsen K, Hatfield J, Iglehart J, Rogers BB, et al. Mycoplasma pneumoniae induces chronic respiratory infection, airway hyperreactivity, and pulmonary inflammation: a murine model of infection-associated chronic reactive airway disease. Infect Immun. 2002;70:649-654.

21. Livak KJ, Schmittgen TD. Analysis of relative gene expression data using real-time quantitative PCR and the 2(-Delta Delta C(T)) method. Methods. 2001;25:402-408.

22. Dassanayake RP, Shanthalingam S, Herndon CN, Subramaniam R, Lawrence PK, Bavananthasivam J, et al. Mycoplasma ovipneumoniae can predispose bighorn sheep to fatal Mannheimia haemolytica pneumonia. Vet Microbiol. 2010;145:354-359.

23. Brinson CW, Lu Z, Li Y, Lopes-Virella MF, Huang Y. Lipopolysaccharide and IL-1beta coordinate a synergy on cytokine production by upregulating MyD88 expression in human gingival fibroblasts. Mol Immunol. 2016;79:47-54.

24. Parham K, Churchward CP, McAuliffe L, Nicholas RA, Ayling RD. A high level of strain variation within the Mycoplasma ovipneumoniae population of the UK has implications for disease diagnosis and management. Vet Microbiol. 2006;118:83-90.

25. Akira S, Uematsu S, Takeuchi O. Pathogen recognition and innate immunity. Cell. 2006;124:783-801.

26. Schroder K, Tschopp J. The inflammasomes. Cell. 2010;140:821-832.

27. Liu YC, Lin IH, Chung WJ, Hu WS, Ng WV, Lu CY, et al. Proteomics characterization of cytoplasmic and lipid-associated membrane proteins of human pathogen Mycoplasma fermentans M64. PLoS One. 2012;7:e35304.

28. You X, Wu Y, Zeng Y, Deng Z, Qiu H, Yu M. Mycoplasma genitalium-derived lipid-associated membrane proteins induce activation of MAPKs, NF-kappaB and AP-1 in THP-1 cells. FEMS Immunol Med Microbiol. 
29. Jiang ZJ, Song FY, Li YN, Xue D, Deng GC, Li M, et al. Capsular polysaccharide is a main component of $M$. ovi in the pathogen-induced Toll-like receptor-mediated inflammatory responses in sheep airway epithelial cells. Mediators Inflamm. 2017;2017:9891673.

\section{Figures}
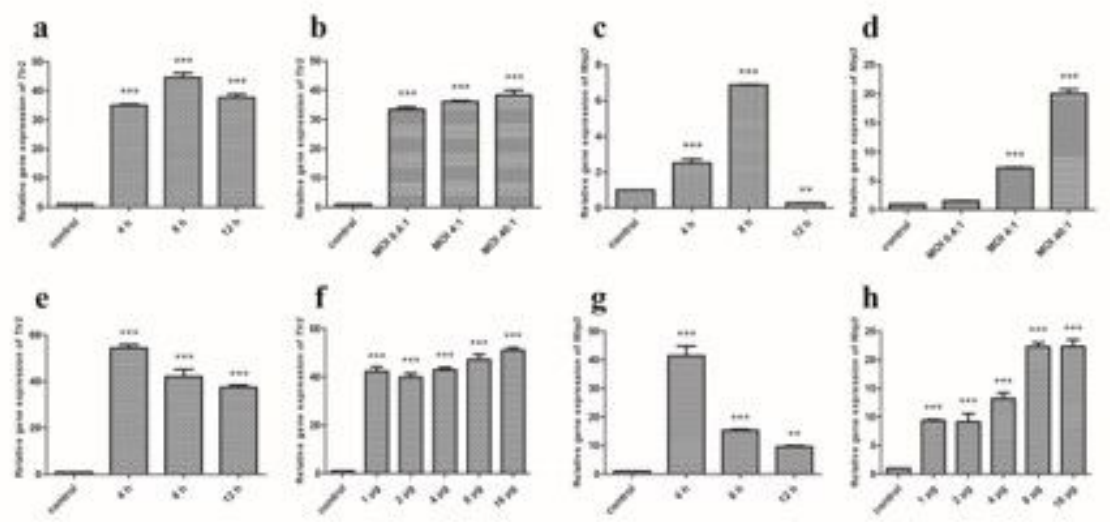

i

j
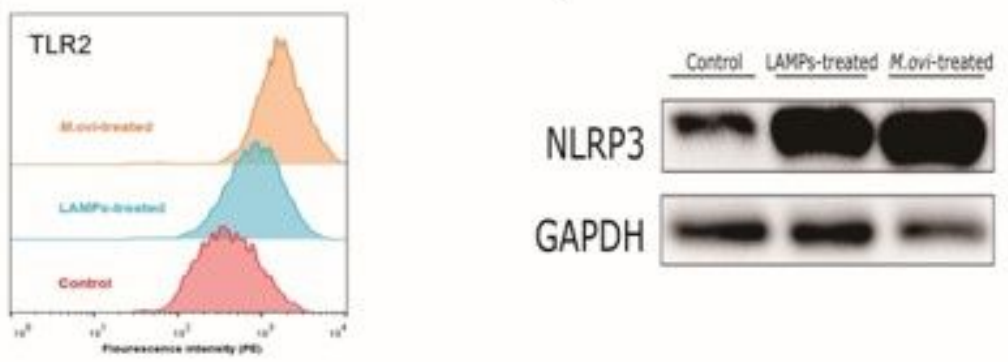

\section{Figure 1}

TLR-2 and NLRP3 inflammasome expression after M. ovi or M. ovi-derived LAMPs infection. TIr2 and Nlrp3 inflammasome mRNA levels standardized to Gapdh from unstimulated (control) and M. oviinfected (MOI 4:1) macrophages at the indicated time points (a, c). Tlr2 and Nlrp3 inflammasome mRNA levels standardized to Gapdh from unstimulated (control) and M. ovi-infected (MOI 0.4:1, 4:1, and 40:1) macrophages at $8 \mathrm{~h}(\mathrm{~b}, \mathrm{~d})$. TIr2 and Nlrp3 inflammasome mRNA levels standardized to Gapdh from unstimulated (control) and M. ovi-derived LAMPs-infected $(8 \mu \mathrm{g})$ macrophages at the indicated time points (e,g). TIr2 and Nlrp3 inflammasome mRNA levels standardized to Gapdh from unstimulated 
(control) and M. ovi-derived LAMPs-infected macrophages at $8 \mathrm{~h}(\mathrm{f}, \mathrm{h})$. Data are presented as the mean and standard deviations of triplicates, and are compared with unstimulated macrophages. Data from one of three representative experiments are shown. TLR2 surface expression by macrophages infected with M. ovi (MOI 4:1), M. ovi-derived LAMPs $(8 \mu \mathrm{g})$, or unstimulated (control) for $16 \mathrm{~h}$ as determined by flow cytometry (i). NLRP3 inflammasome protein expression by macrophages infected with M. ovi (MOI 4:1), M. ovi-derived LAMPs $(8 \mu \mathrm{g})$, or unstimulated (control) for $16 \mathrm{~h}$ determined by western blotting; GAPDH was used as a loading control (j). Data from are representative of three experiments. Results are expressed as means \pm standard deviations of three independent experiments and were analysed by oneway analysis of variance (ANOVA) followed by Tukey's multiple comparisons test or with two-way ANOVA with Bonferroni's post-hoc test. ${ }^{*} \mathrm{P}<0.05 ;{ }^{*} \mathrm{P}<0.01 ; * * * \mathrm{P}<0.001$.
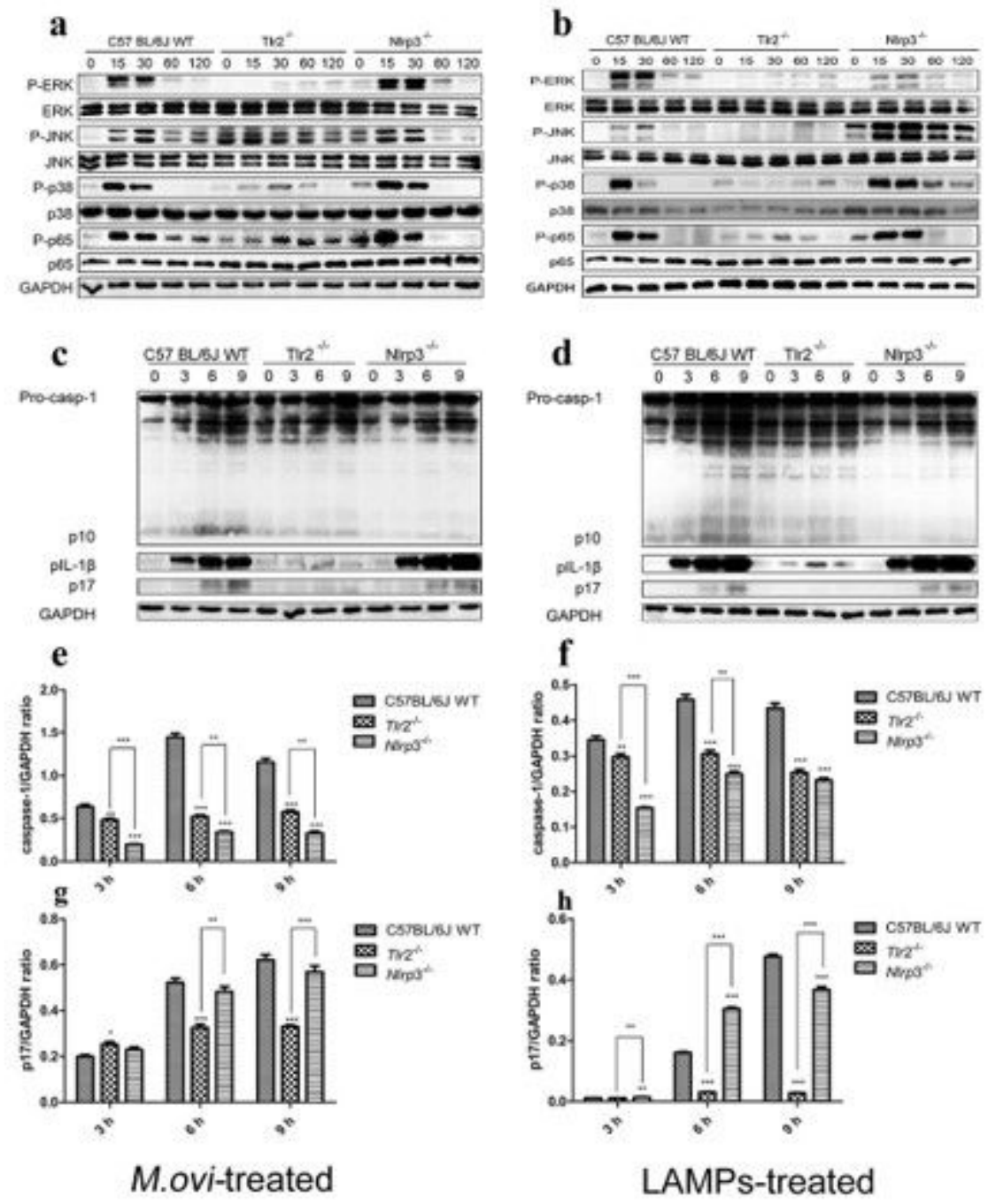

Figure 2

Host TLR2 mediated signalling activation in macrophages after M. ovi or M. ovi-derived LAMPs infection. Activation of MAPK (P-ERK, P-JNK, and P-p38), NF-KB (P-p65), and caspase-1 (p10, pIL-1 $\beta$, and p17) 
pathways evaluated by western blotting; GAPDH was used as a loading control $(a-d)$. Grayscale values were measured using Image J software $(e-h)$. Results are expressed as means \pm standard deviations of three independent experiments and were analysed by one-way analysis of variance (ANOVA) followed by Tukey's multiple comparisons test or with two-way ANOVA with Bonferroni's post-hoc test. ${ }^{*} \mathrm{P}<0.05$; ${ }^{*} \mathrm{P}<$ $0.01 ; * \star \star P<0.001$.
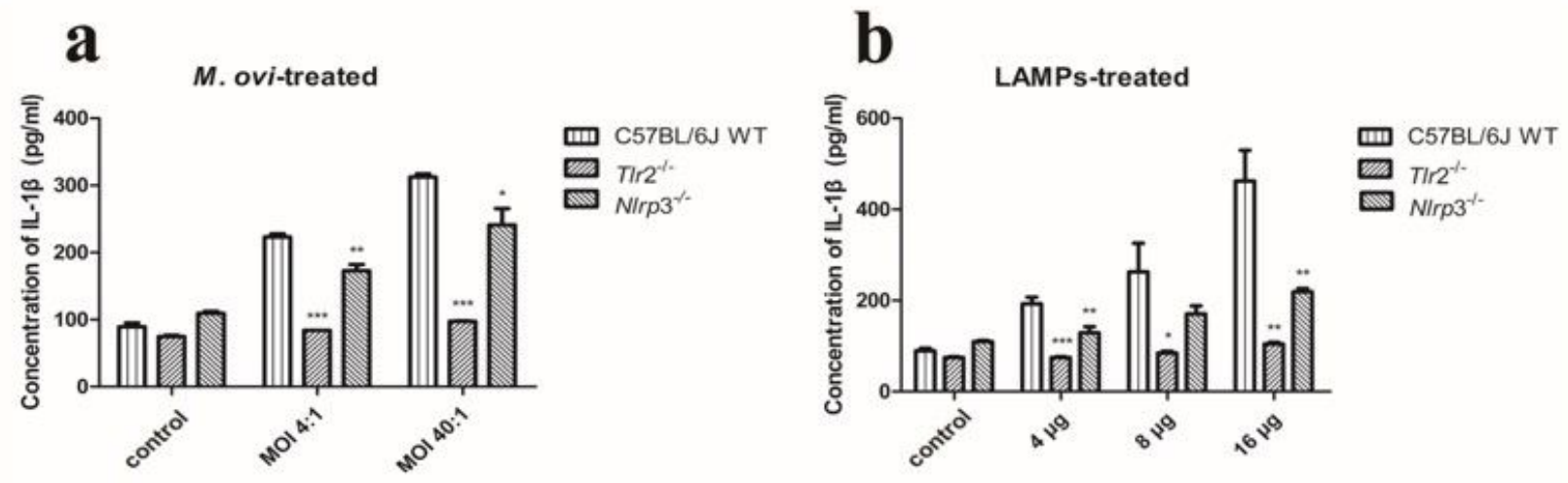

\section{Figure 3}

TLR2 and NLRP3 stimulate macrophage-induced proinflammatory cytokine secretion after M. ovi or M. ovi-derived LAMPs infection. Wild-type (WT) and corresponding gene-deficient macrophages were infected with M. ovi or M. ovi-derived LAMPs or were uninfected as controls. IL-1 $\beta$ production in the supernatant of macrophage cultures was analysed by ELISA $9 \mathrm{~h}$ after infection $(\mathrm{a}-\mathrm{d})$. Results are expressed as means \pm standard deviations of three independent experiments and were analysed by oneway analysis of variance (ANOVA) followed by Tukey's multiple comparisons test or with two-way ANOVA with Bonferroni's post-hoc test. ${ }^{*} \mathrm{P}<0.05 ;{ }^{* *} \mathrm{P}<0.01 ; * \star * \mathrm{P}<0.001$.

\section{Supplementary Files}

This is a list of supplementary files associated with this preprint. Click to download.

- NC3RsARRIVEGuidelinesChecklistfillable.docx 